\title{
A Comparative Analysis of Undergraduate Education between China and the United States ---Taking International Economics as an Example
}

\author{
Yan-qiu Wu, Jie Yao
}

School of Economics and Management, Northeast Dianli University, Jilin, Jilin, China

\begin{abstract}
The United States is one of the countries with the highest quality of education in the world, and there are a lot of world-renowned universities in this country. The similarities do exist in university education of China and the United States, but there are much more differences between the two countries. This essay compares the teaching of the course International Economics, discussing the differences instruction approaches, the way of thinking, assignment and evaluation between China and the United States. The intention of the paper is to understand the features of Chinese and American undergraduate education in depth, and provide enlightenment on promoting Chinese university curricula reform and development.
\end{abstract}

Keywords - Comparative analysis; International economics; China and United States; Undergraduate education

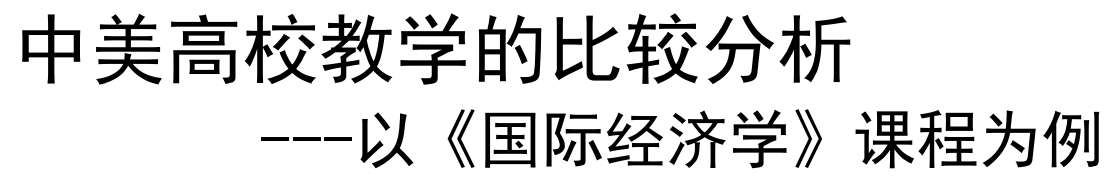

\author{
吴艳秋 姚洁 \\ 东北电力大学经济管理学院, 吉林, 吉林, 中国
}

摘 要 美国是世界上教学质量最高的国家之一,有很多世界知名大学。中美之间在大学教育上存在着相似性,但更多的是存在着 差异。本文比较了中美高校在《国际经济学》课程的教学, 从教学方法、思维方式和课时分配与课程评价等方面的差异进行比较分析。 从而更加深入的了解中美本科教育的特点,希望能在推动中国大学课程改革与发展提供启示。

关键词＼cjkstart比较分析，国际经济学，中美，高校教育

\section{1. 中国国际经济学教学的现状与特点}

\section{1 过多的依靠多媒体，阻碍了课堂交流}

目前中国大学课堂上国际经济学教学基本是依靠多媒 体, 教师放映课件, 学生拷贝课件, 上课的节奏很快, 学 生仅靠听觉掌握信息, 师生时间思路出现脱节, 教学互动 不很理想。多媒体在教学推演中有很大的局限性, 使得上 课的内容抽象化, 学生的思维往往跟不上多媒体的展示, 教学效果大打折扣。另外, 依赖多媒体助长了老师的惰性, 很多老师因为久而久之动笔少, 而不能熟记一些内容, 一 定程度上影响了教师对课程总体与细节的把握。多媒体教 学的内容固定, 使得教学过程中师生缺乏灵感。多数老师 仅仅是利用多媒体来展示课件, 而不能深入挖掘多媒体带
来更多的视觉、听觉、动态、连续、前沿、多信息等功能。 很多教师的备课是 “一劳永逸”, 每次更新的内容较少, 知 识相对陈旧。在多媒体教师也有黑板, 但是黑板上多数是 草草几个字, 或者当成草稿纸, 传统的教学优势受到抑制。

\section{2 教学内容与层次划分不清}

在国际经济学教学内容上, 本科生与研究生划分的标 准、定位出现很多的版本。尤其很多层次低、排名靠后的 学校, 为了满足学生报考研究生的需要, 加大了国际经济 学教学的难度, 超过了学生承受能力, 很多学生叫苦连天, 甚至出现了厌学的现象。本来排名靠后的学校学生基础就 弱, 现在还要学的更加深入, 教学效果出现严重的两极分 
化, 真正学得好的人不多。本科生的国际经济教学关键是 入门教育, 培养学生的经济学兴趣, 掌握基本的经济知识 原理, 对国际经济政策能得知其中的来龙去脉, 对政策效 果能有一定的判断与理解, 研究生的经济教学则是要深入 挖掘国际经济规律, 国际经济学原理的推导, 掌握国际经 济学方法、模型、处理技巧, 解析国际经济问题。所以在 本科生与研究生国际经济学教学中划分层次鲜明, 框定各 层次国际经济学教学的大纲, 这样就算是考研, 大家也不 用费尽心力弄些五花八门的资料。

\section{3 作业与考试处于传统模式}

目前国际经济学的作业形式单一, 多数是停留在书面 上的名词解释、选择题、计算、简答, 这样的作业不足以 锤炼学生的素质, 难以适应社会的发展。学生有了惰性, 老师也有了惰性, 渐渐地作业越来越少, 抄袭越来越严重, 批改的次数越来越稀疏。对于国际经济学考试多数学校是 按照 80\%: $20 \%$ 或者 70\%: 30\%的比例最终核算学生成绩, 前者指期末成绩, 后者指平时的出勤、作业成绩。因为平 时成绩拉不开, 关键还是期末考试一锤定音, 这样的考核 机制使得经济学考试变成了突击考试, 很多学生鳌上几晚 就将高分收入囊中。

\section{4 第二课堂缺失}

对于国际经济学的教学不仅是课堂活动, 更应该是全 方位的活动。首先是网络互动平台, 很多学校也建立了平 台, 但是利用率不高, 经常冷冷清清, 关键是没有话题。 经营好网络互动平台, 使学生愿意、积极主动参与平台, 是目前需要解决的主要问题。科研相长是高校提高教学质 量的一个关键途径。现在的课题研究中, 教师往往忽略本 科生这支生力军, 尤其是教学课题中本应该是主角的本科 生更是找不到影子, 因为多数教师不坐班, 使得学生很少 有机会到办公室找老师直接交流, 而课下因为时间有限也 使得学生很难与老师面对面地交流。第二经济课堂基本处 于空白, 或者空置状态。

\section{2. 美国大学《国际经济学》课程教学的特点}

\section{1 教学内容丰富, 时代感强}

笔者深入美国大学课堂长达七周之久, 经常亲眼目睹 教师带着各种最新的经济资讯材料来上课, 如: 国际经济 新闻, 就是教学内容中的一项, 教师经常会在课堂上将今 天网上或者是电视上的最新新闻复印后分发给大家, 进行 学习和讨论, 所运用的分析与讨论工具就是在课堂上刚刚
学到的国际经济学理论, 如用关税效应分析模型, 来分析 美国关税与经济发展等方面的问题。这些教学内容, 让学 生感到新鲜, 也让他们理解到国际经济学与社会接触的亲 密, 让学生认识到, 自己的课堂学习是有用的、有价值的, 能够运用到实际生活中去的, 这可以增强学生的学习兴趣 和学习成就感, 培养运用国际经济学理论解决实际经济问 题能力。

另外, 以国际经济学游戏作为一种重要的教学内容和 教学手段, 是美国犹他州里大学乃至很多其他大学国际经 济学课程教学内容时代感强的又一鲜明表现。教师会经常 在课堂上穿插一些小游戏, 这样就使得那些枯燥的理论边 的不那么难接受了。

\section{2 课程教学内容重点突出}

教师在课堂上授课时, 鲜见完整的知识体系, 凡是教 师在课堂上介绍的, 都是国际经济学课程中的重点和难点, 凡是本课程的重点和难点, 教师都会在课堂上进行集中解 释。之所以这样安排, 不是因为其他考虑, 而是因为在美 国的教育理念中, 学生自主性和能动性的发挥一直占据着 重要的位置, 所以, 从小学开始直至大学, 美国学生的课 堂时间都比中国学生的课堂时间要短很多, 为何作此安排, 因为学生要自主能动, 首先就需要有自己控制的时间和空 间, 只有压缩学生的课堂时间, 才能给学生更多的时间进 行自学和社会实践。同时, 学生又不可或缺地需要教师给 予学习方法、学习内容等方面的指导, 因此, 课堂教学的 主要任务就调整为对学生进行学习方法和学习内容等的指 导, 如何在短暂的课堂教学时间内实现指导效率的最大化。 教师只在课堂上讲授重点和难点的部分, 其余的非重点和 非难点的部分, 留给学生自己课后去自学, 然后, 带着问 题返回课堂, 到课堂上寻找解决问题的方法和问题的答案

\section{3 学生成绩考核方案全面、灵活多样化}

由于每一门大学课程的内容、特点、授课教师、教学 对象以及对学生的要求、培养目标等方面都具有一定的差 异, 因此, 在美国大学的众多课程教学中, 很难看到雷同 的两套学生成绩考核方案。在每门课程教学的第一次课上, 教师都会给每个学生发一份教学大纲, 而大纲内教师重点 解释说明的一个重要内容, 就是学生的成绩考核方案, 这 实质上就是教师对学生提出关于本门课程的明确而具体的 要求。美国大学微观经济学课程学生成绩考核方案具体表 现在:

美国犹他州里大学国际经济学课程的学生考核方法很 独特, 其构成要素比较多, 具体构成及其各构成要素在学 
生考核总评分中所占比重如表 1 所示:

表1. 美国犹他州立大学国际经济学课程成绩考核分布表

\begin{tabular}{l|c}
\hline 构成要素 & 在学生考核总评分中所占比重 $(\%)$ \\
\hline 三次平时考试 & 40 \\
一次期末考试 & 20 \\
学生出勤及课堂表现 & 20 \\
小组合作论文项目 (PPT) & 20 \\
\hline
\end{tabular}

众多的考核构成要素, 有个字不同的考核重点: 三次 平时考试注重对学生阶段性的学习进行集中考核, 试题主 要偏重于理论知识方面, 并且在三次考试中, 学生可以去 掉成绩最低一次; 学生出勤及在课堂上的平时表现, 注重 考核学生的学习态度和课后自学的效果及自我表现的能 力, 偏重于对学生学习态度的考核, 教师无一例外地每次 课上点名, 并当众给学生打平时考勤分; 小组合作论文写 作, 注重于对学生的合作能力及书面表达、逻辑构架等能 力进行考核, 偏重于学生合作能力的考核, 并且要求学生 进行 PPT 演示, 这有锻炼了学生的演讲能力。

以上四种考核构成要素, 囊括了考核的方方面面, 各 要素所考核的对象各异、目标不同、方式方法也有较大差 异, 因此, 这套学生成绩考核体系较为全面, 科学合理。

\section{4 国际经济学课程学习注重理论联系实际}

美国国际经济学的教学, 不论是在教学手段、教学 内容还是在考核方式上, 都非常注重理论联系实际。

教师在涉及课堂教学时, 就充分考虑理论联系实际 这条原则的运用, 如在美国犹他州立大学的国际经济学 课堂上就时常会有课堂游戏, 这种既有理论又有实践的 教学手段很吸引学生的注意力, 学生们活动积极踊跃, 笔者也参与其中。

教学内容有理论有实践, 理论表现在一些重要的概 念和理论的介绍方面, 如关税与非关税壁垒的概念以及 关税的效应理论等; 而实践表现为丰富多样的经济案例, 来自现实生活的国际经济现象、国际经济问题和国际经 济模式, 如原油涨价对欧盟国家及美国所造成的影响等, 所有这些构成了整个的教学内容, 因此, 这样的教学内 容安排是理论联系实际的。

国际经济学教师选用了三种方式, 对学生进行成绩 考核, 这三种方式分别是: 考试、平时表现、课堂内游 戏及论文。其中, PPT 演示及平时表现侧重对实际能力 的考核现在游戏, 考试及论文侧重对国际经济学理论的 考核, 因此, 教师综合运用这三种方式进行学生成绩考
核, 充分体现了理论联系实际的考核方式选用原则。

\section{3. 中国高校《国际经济学》课程教学需改进方面}

国际经济学的基础性和抽象性, 会给课程教学造成一 些难点, 许多中国学生在学习国际经济学过程中遇到“难”、 “空”、“闷”等问题。国际经济学很容易成为学生难过的 课程之一。美国式发达国家, 在市场经济建设方面, 比中 国的市场经济早了很多年, 美国大学的国际经济学学科建 设同样比中国大学的国际经济学学科建设早了很多。在零 距离地进入美国大学微观经济学课堂进行参与和观察之 后, 在总结美国大学国际经济学课堂教学的特点的基础上, 提出了如下几点供中国大学国际经济学课程教学借鉴。

\section{1 进一步丰富教学方法}

由于中国大学生, 尤其是大三年级的大学生 (国际经 济学属于专业课程, 一般面向高年级大学生开设) 课后时 间都很少, 而课堂内的时间比较多, 因此, 根据这种实际 情况, 可以通过教学方法的改革, 使学生感到课堂教学的 丰富多彩, 教师除了运用传统的讲授法进行教学之外, 还 可以安排小组讨论、分组游戏、课堂作业、在教室的指导 下自助学习等, 通过多种教学方法的综合使用, 既满足了 学生作为成人要求自主学习的心理, 又吸引和培养了学生 对国际经济学课程的学习兴趣, 提高了专业素养和能力。 特别是小组讨论和分组游戏值得在中国大学的国际经济学 课堂推荐试用。以上教学方法的综合和恰当的运用可极大 地调动学生学习的积极性和主动性, 更好地帮助学生从宏 观上去把握国际经济学的相关理论内容, 当学习的脉络比 较清晰时, 学习的动力自然就增加了。如何达到更高的教 与学的和谐统一, 需要大量的教学实践, 从实践中总结经 验, 才能提高教学质量, 达到理想的教学效果。

\section{2 联系实际, 依托网络大胆革新教学内容}

国际经济学来源于社会生产实际, 又指导现实经济的 发展, 其学习的最高境界莫过于能运用经济学的分析方法 和理论工具分析和解决国际经济的实际问题。这要求教师 在课堂教学中不能一味枯燥地讲理论, 而要善于随时将经 济发展中的有代表性的事件与课本中的理论相结合, 培养 学生吧所学的知识融会贯通的能力。同时依托网络, 能充 分发挥现在社会的网络信息传播迅速、方便获取的优势, 教师可以将网络经济资讯引入到教学课堂上来, 引导学生 运用所学微观经济学理论进行经济资讯的分析推理活动, 教给学生理论联系实际的方法。同时, 还可以推荐一些相 关网站, 让学生课后汶览, 并布置相关的课后作业, 如通 
过写论文、做 PPT 演讲等方式将收集到的信息进行整理分 析阐述并得出结论。

\section{3 适度调整学生成绩考核方案}

改变目前主要依靠考试, 尤其是期末考试, 对学生成 绩进行考核的现状, 增加考核构成要素的种类, 如课堂参

与、课后作业、平时测验、分组游戏、论文写作、PPT 演 讲等, 并分散各项构成要素占学生成绩总评分的比重, 在 考核的过程中, 着重体现全面考核、过程考核和能力考核 的思想。例如, 应用 Presentation 为基础的参与式教学法可 以激发学生的学习兴趣、掉的那个学生潜能和创新精神、 提高学生的自信心、团队合作能力和自我表现的能力。

\section{4 彻底改变高校教师的工作服务态度}

中国高校教师要学习美国老师嗔嗔业业精神, 有板有 眼, 步步为营夯实国际经济学基础。根据美国老师评价指 标, 老师是否激发、培育学生兴趣是非常重要的一条。所 以我国高校老师更应该全心全意服务学生。向美国一样, 每周应该安排老师一定的坐班时间, 与学生直接交流。利 用好教学互动平台, 可以没两周给定一个主题, 以竞赛的 形式收集学生经济学智慧, 对于优胜者给予一定物质或者 精神奖励。

\section{4 总结}

中国大学传承了整齐划一的严格训练的传统, 过程虽 然痛苦但 “成品率” 较高。美国大学的教育重视个体差异, 让每个人的特点尽情发挥, 然后再以冥冥之中自然成才的 概率来收获。孰优孰劣, 又要回到 “大学教育最重要的是
什么” 这个基本问题。美国大学在国际经济学的课程中力 图使学生通过一门课 “know something about everything”; 而中国的国际经济学课程则要求学生 “know everything about something”, 想以最快的速度使学生进入国际经济学 这一课程的研究殿堂。中国大学国际经济学的部分教学内 容在美国是研究生阶段讲授的, 这使本科生的专业素养整 体较高; 而美国国际经济学本科教育鼓励学生个性发展, 学 生间个体差异的增大, 为创新型人才的脱颖而出提供了土 壤。两种方法产生的顶尖人才都是优秀的, 但在对人才的 创新能力培养上, 美国大学似乎要略胜一筹。

\section{参考文献(References)}

[1] Shu Dingfang. The goal and direction of the reform of university English teaching, Journal of Northeast Normal University: Philosophy and Social Sciences edition, 2012, (1).Jilin: China.

[2] $\mathrm{Hu}$ Shouhua. The differences between Chinese and western education, Heilongjiang science and technology information, 2010 (2).Heilongjiang: China.

[3] Michael M.crow, American education systems in a global context. Technology in society, 2008(3):279-291.NewYork: The United States.

[4] Jiang Lai, Analysis of the Difference of Undergraduate Education between China and the United States, Comparative Education Review.2005 (8). Shanghai: China.

[5] Jinglei Zhang, Suping Liu, A Comparative Study of Teaching Supervision between China and the United States, Journal of Yangzhou University,2012(1). Yangzhou: China. 